\title{
Erratum to: Influence of Heat Treatment on Microstructure and Sliding Wear of Thermally Sprayed Fe-Based Metallic Glass Coatings
}

\author{
Guang Liu $\cdot$ Yulong An $\cdot$ Jianmin Chen \\ Guoliang Hou $\cdot$ Jie Chen
}

Published online: 11 May 2012

(C) Springer Science+Business Media, LLC 2012

Erratum to: Tribol Lett (2012) 46:131-138

DOI 10.1007/s11249-012-9929-4

In the original version of this paper, the appearance of the authors' affiliations were incorrect. They appear correct in this erratum.

The online version of the original article can be found under doi:10.1007/s11249-012-9929-4.

G. Liu $\cdot$ Y. An $\cdot$ J. Chen $(\bowtie) \cdot$ G. Hou $\cdot$ J. Chen

State Key Laboratory of Solid Lubrication, Lanzhou Institute of Chemical Physics, Chinese Academy of Sciences,

Lanzhou 730000, China

e-mail: chenjm@1zb.ac.cn

G. Liu · G. Hou · J. Chen

Graduate School, Chinese Academy of Sciences,

Beijing 100049, China 